\title{
Fire Apparatus Driver Operator Suffers Fatal Cardiac Event During Fire Department Training - Maryland
}

\section{Executive Summary}

On May 30, 2014, a 58-year-old Fire Apparatus Driver Operator (FADO) participated in his fire department's (FD's) annual physical ability test, known as their “physical readiness assessment." The physical readiness assessment (PRA) involved completion of an untimed event of eight job tasks. Following this assessment, the FADO attempted a self-contained breathing apparatus (SCBA) maze drill. The FADO completed the eight job tasks without difficulty, but had sudden onset of severe shortness of breath during the SCBA maze drill. While in the maze, the FADO collapsed. The FADO was removed from the maze training prop and on-scene emergency medical service (EMS) began advanced cardiac life support and transported the FADO to the emergency department (ED). Despite resuscitation efforts on-scene, during transport, and in the ED, the FADO died. The death certificate and autopsy report, both completed by the Medical Examiner's office, listed the cause of death as "atherosclerotic cardiovascular disease.” The autopsy reported moderate to severe focal coronary artery atherosclerosis, an enlarged heart (cardiomegaly), and left ventricular hypertrophy. Based on the autopsy findings and the clinical scenario, NIOSH investigators conclude that the physical exertion associated with the physical readiness assessment and SCBA maze training triggered the FADO's sudden cardiac death.

\section{Key Recommendations}

- Ensure that all fire fighters receive an annual medical evaluation consistent with NFPA 1582, Standard on Comprehensive Occupational Medical Program for Fire Departments

- Ensure fire fighters are cleared for duty by a physician knowledgeable about the physical demands of firefighting, the personal protective equipment used by fire fighters, and the various components of NFPA 1582

- Phase in a mandatory comprehensive wellness and fitness program for fire fighters.

The following recommendation would not have prevented the FADO's death, but NIOSH investigators include them to address general safety and health issues:

- $\quad$ Consider providing on-scene emergency medical services with advanced life support and transport capability during the PRA as is recommended during live fire training

- Adopt procedures to make sure that firefighters are properly supervised while they are doing training. 


\section{Fire Apparatus Driver Operator Suffers Fatal Cardiac Event During Fire Department Training - Maryland}

The National Institute for Occupational Safety and Health (NIOSH), an institute within the Centers for Disease Control and Prevention (CDC), is the federal agency responsible for conducting research and making recommendations for the prevention of work-related injury and illness. In 1998, Congress appropriated funds to NIOSH to conduct a fire fighter initiative that resulted in the NIOSH "Fire Fighter Fatality Investigation and Prevention Program" which examines line-of-duty-deaths or on duty deaths of fire fighters to assist fire departments, fire fighters, the fire service and others to prevent similar fire fighter deaths in the future. The agency does not enforce compliance with State or Federal occupational safety and health standards and does not determine fault or assign blame. Participation of fire departments and individuals in NIOSH investigations is voluntary. Under its program, NIOSH investigators interview persons with knowledge of the incident who agree to be interviewed and review available records to develop a description of the conditions and circumstances leading to the death(s). Interviewees are not asked to sign sworn statements and interviews are not recorded. The agency's reports do not name the victim, the fire department or those interviewed. The NIOSH report's summary of the conditions and circumstances surrounding the fatality is intended to provide context to the agency's recommendations and is not intended to be definitive for purposes of determining any claim or benefit.

For further information, visit the program website at www.cdc.gov/niosh/fire or call toll free 1-800-CDC-INFO (1-800-232-4636). 


\section{Fire Apparatus Driver Operator Suffers Fatal Cardiac Event During Fire Department Training - Maryland}

\section{Introduction}

On May 30, 2014, a 58 year-old FADO experienced a fatal cardiac event while performing the FD’s annual PRA. NIOSH was notified of this fatality on June 2, 2014, by the U.S. Fire Administration. NIOSH contacted the affected fire department on June 3, 2014 to obtain additional information. A contractor for the NIOSH Fire Fighter Fatality Investigation Team (the NIOSH investigator) contacted the FD to schedule the investigation which took place on October 20, 2014.

During the investigation, the NIOSH investigator interviewed the following people:

- Assistant Chief of the FD

- Crew members who were training with the $\mathrm{D} / \mathrm{O}$ at the time of the event

- Wife of the FADO

The NIOSH investigator reviewed the following documents in preparing this report:

- FD standard operating procedures

- Witness statements taken the day of the event

- Ambulance pre-hospital care report

- Emergency department medical records

- Death certificate

- Medical examiner's report

- Primary care physician (PCP) medical records

- Medical records from FD where FADO was a volunteer

\section{Investigation}

On May 30, 2014, the FADO arrived at his fire station at 0600 hours for his shift which began at 0700 hours. During the morning hours, the FADO completed routine chores that included inspecting and washing the Engine, and sweeping the station bay. At mid-morning, the FADO and a crewmember were mowing the lawn with a push mower when they were dispatched to a medical call. It was a minor call and the FADO never exited the fire engine. Upon returning to the station, the FADO and the crewmember finished mowing the lawn which took about 30 minutes. Late morning weather conditions were mostly cloudy, with an air temperature of approximately $63^{\circ} \mathrm{F}$ and relative humidity 75\% [Weather Channel 2014].

At approximately 1300 hours, the FADO and his crew reported to the training academy for their annual PRA. The PRA consists of an untimed test of eight essential job tasks involving eight stations: tire drag, wall climb, hose drag, carrying a high rise pack to the roof and hoisting/lowering a high rise pack, ladder extension, ceiling push/pull (simulating overhaul), tower climb, and a crawl. The FADO 


\section{Fire Apparatus Driver Operator Suffers Fatal Cardiac Event During Fire Department Training - Maryland}

was the first person to complete the course, doing so in approximately 9 minutes. Waiting for 30 to 45 minutes for his other crewmembers to finish, the FADO was talking and joking and in no apparent distress. At this time, air temperature was $68^{\circ} \mathrm{F}$, relative humidity was $59 \%$, wind was $6.9 \mathrm{mph}$, and it was mostly cloudy [Weather Channel 2014].

About 1355 hours, the FADO and a crewmember began the SCBA maze prop. The maze was in a large shipping container outfitted with several obstacles that firefighters navigated while wearing full PPE, including SCBA and face mask. Approximately halfway through the maze (about 8 minutes into the exercise), the FADO began breathing heavily and took his SCBA regulator off. When the other crewmember asked how he was doing, the FADO responded that he needed to take a break and sit down. When asked if he wanted to take a break here or continue a short distance to a platform, the FADO didn't respond but kept moving forward. As the FADO was assisted up a set of steps to a raised platform, he collapsed.

The crewmember with the FADO immediately banged on the side of the shipping container to alert others, activated the FADO's Personal Alert Safety System (PASS) device, and exited the maze to summon help. The crew's Captain, hearing the banging, immediately entered the maze and began to extract the FADO. The crewmember ensured 911 was called (1405 hours) and then returned to help remove the FADO from the maze.

The FADO was carried down a flight of stairs and removed from the maze prop through the front door. An ambulance crew was also on site doing training and the paramedic from that ambulance ran to the maze while the EMT brought the ambulance to the FADO's location. At 1410 hours the FADO was placed on a cardiac monitor which showed ventricular fibrillation. The FADO was defibrillated (shocked), an intravenous line was inserted, and cardiac resuscitation medications were administered. Intubation attempts were unsuccessful as the ambulance departed the scene at 1420 hours with cardiopulmonary resuscitation (CPR) in progress. Enroute to the ED the FADO received additional cardiac drugs and was defibrillated a second time - all without a change in clinical status.

The ambulance arrived at the ED at 1429 hours. The cardiac monitor showed pulseless electrical activity. Advanced cardiac life support measures, including cardiac medications, and CPR were continued for approximately 25 minutes in the hospital. After a cardiac ultrasound confirmed no cardiac activity, the FADO was pronounced dead and resuscitation efforts were discontinued (1455 hours).

\section{Medical Findings}

The death certificate and autopsy, both completed by the Assistant Medical Examiner, listed the cause of death as "atherosclerotic cardiovascular disease.” Pertinent autopsy findings included severe coronary artery atherosclerosis (90\% stenosis of the first diagonal branch of the left anterior descending artery and 75\% stenosis of the left anterior descending artery), an enlarged heart (cardiomegaly), and left ventricular hypertrophy. No coronary thrombosis, plaque hemorrhage, or dissection was noted. See Appendix A for more detailed autopsy information. 


\section{Fire Apparatus Driver Operator Suffers Fatal Cardiac Event During Fire Department Training - Maryland}

The FADO had long-standing hypertension. Although unclear when first diagnosed, he had been taking hypertensive medications since at least 2007. The FADO had an annual FD medical evaluation in October 2013, provided by the FD where he served as a volunteer firefighter. At this examination, his blood pressure was 116/78 millimeters of mercury (mmHg) and his laboratory test results included total cholesterol of $189 \mathrm{mg} / \mathrm{dL}$ (desirable $<200 \mathrm{mg} / \mathrm{dL}$ ), high density lipoprotein (HDL cholesterol) of $38 \mathrm{mg} / \mathrm{dL}$ (low < $40 \mathrm{mg} / \mathrm{dL}$ ), low density lipoprotein (LDL cholesterol) of $99 \mathrm{mg} / \mathrm{dL}$ (optimal < 100 $\mathrm{mg} / \mathrm{dL}$ ) and triglycerides of $262 \mathrm{mg} / \mathrm{dL}$ (high 200-499 mg/dL) [National Cholesterol Education Program 2002]. The FADO also completed a treadmill stress test (using a modified Bruce protocol with shortened durations of stages) in which he exercised for $51 / 2$ minutes and achieved 13.5 metabolic equivalents (METs) according to the physician notes. His highest heart rate was 174 beats per minute (107\% of age-predicted maximal heart rate), his highest blood pressure reading was 180/90 mmHg, and the electrocardiogram (EKG) tracing showed no signs of ischemia or arrhythmias.

The FADO denied a family history of cardiovascular disease. He was a non-smoker who did not exercise regularly but was active as a volunteer firefighter and as an instructor at the State Fire Academy. The FADO was 67 inches tall and weighed about 232 pounds, giving him a body mass index of 36 kilograms per meter squared [CDC 2014].

\section{Fire Department}

This FD consists of 1,050 career members and approximately 2,000 volunteers. The department operates out of 25 career stations and 33 exclusively volunteer stations within the county. The volunteer companies function as independent fire departments, which operate under the county deployment plan. The stations serve a population of more than 800,000 people in a geographic area of approximately 612 square miles of land and 28 square miles of waterways.

\section{Employment, Preplacement Medical Evaluation, and Training}

The FD requires applicants to take a general aptitude test, complete a physical ability test, and be interviewed. Top candidates must pass a pre-placement medical evaluation before they are hired. Components of this medical evaluation include:

- A complete medical history and questionnaire

- Height, weight, and vital signs

- Physical examination

- Vision test

- Hearing test

- Blood tests: Complete blood count (CBC), chemistry panel which includes lipid measurements

- Urinalysis

- Urine drug test

- Spirometry (lung function tests)

- Resting EKG

- Vision test 


\section{Fire Apparatus Driver Operator Suffers Fatal Cardiac Event During Fire Department Training - Maryland}

- Hearing test

The FADO was hired in 1986 and was promoted to FADO in 1999. He was also a certified Emergency Medical Technician.

\section{Periodic Medical Evaluations/Return to Work Medical Evaluations}

The FD does not provide annual medical evaluations for members, but they do have standard operating procedures which indicate that personnel must obtain a yearly physical. Members should use FD provided insurance to see their own primary care physician (PCP) and be medically cleared annually. The employee provides their PCP with a copy of their current job description before they are evaluated and provide a form which the evaluating physician must sign indicating the firefighter is medically cleared for firefighting. The FADO had yet to complete his annual physical requirement at the time of his death. However, the FADO was a volunteer firefighter at another FD that also required annual medical evaluations. The medical evaluation of the FADO at his volunteer FD resulted in the FADO being cleared for unrestricted duty.

\section{Fitness/Wellness Programs}

The FD has standard operating procedures that outline the role of the FD and the Union in supporting a fitness and wellness program. Fire stations have exercise equipment and a Battalion Health Coordinator (who is certified as an IAFF/IAFC Peer Fitness Trainer) serves as the first line of contact for fitness related issues. As part of the Physical Fitness Program, each career member of the department must attempt a physical fitness assessment annually that includes; a 1.5 mile run, modified sit-ups and push-ups. Furthermore, members must participate in an annual PRA.

\section{Discussion}

\section{Sudden Cardiac Events.}

The most common risk factor for cardiac arrest and sudden cardiac death is coronary heart disease (CHD), defined as the build-up of atherosclerotic plaque in the coronary arteries [AHA 2012]. Risk factors for CHD include three non-modifiable factors (age older than 45, male gender, and family history of CHD) and six modifiable factors (smoking, hypertension, high blood cholesterol, obesity, physical inactivity, and diabetes mellitus) [AHA 2012; National Cholesterol Education Program 2002]. The FADO had three of these risk factors (male, hypertension and obesity).

The narrowing of the coronary arteries by atherosclerotic plaques occurs over many years, typically decades [Libby 2008]. However, the growth of these plaques probably occurs in a nonlinear, often abrupt fashion [Shah 1997]. Most heart attacks occur when a vulnerable plaque ruptures, causing a blood clot to form and occlude a coronary artery. Establishing a recent (acute) heart attack requires one or more of the following: characteristic EKG changes elevated cardiac enzymes, or coronary artery thrombus. In this case, the FADO did not have a heart rhythm that could be analyzed for ischemic changes on his EKG, he died before cardiac enzymes would become elevated, and no thrombus was identified at autopsy. However, heart attacks can occur without evidence of a coronary thrombus [Davies 1992; Far et al. 1995]. 


\section{Fire Apparatus Driver Operator Suffers Fatal Cardiac Event During Fire Department Training - Maryland}

Sudden cardiac death can also be caused by primary cardiac arrhythmias (disruption in the electrical signal of the heart). Therefore, either a heart attack or a primary cardiac arrhythmia could have been responsible for his death.

\section{Cardiomegaly/Left Ventricular Hypertrophy (LVH)}

The autopsy revealed that the FADO had cardiomegaly and mild left ventricular hypertrophy. Both conditions independently increase the risk for sudden cardiac death [Levy et al. 1990]. Hypertrophy of the left ventricle is relatively common among individuals with long-term hypertension, a heart valve problem, or chronic cardiac ischemia (reduced blood supply to the heart muscle) [Siegel 1997]. The FADO had a history of hypertension and probably had ischemia due to his underlying CHD. Therefore, both conditions probably contributed to his cardiomegaly and LVH.

\section{Physiological Stress of Firefighting}

Firefighting is widely acknowledged to be physically demanding. Firefighting activities require fire fighters to work at near maximal heart rates for long periods. An increase in heart rate typically occurs in response to the initial alarm and persists throughout the course of fire suppression activities [Barnard and Duncan 1975; Lemon and Hermiston 1977; Manning and Griggs 1983; Smith et al. 2001]. Even when energy costs are moderate (as measured by oxygen consumption) and work is performed in a thermoneutral environment, heart rates may be high (over 170 beats per minute) owing to the insulated properties of the personal protective clothing [Smith et al. 1995].

Epidemiologic studies in the general population have found that heavy physical exertion can trigger a heart attack and/or sudden cardiac death [Tofler et al. 1992; Mittleman et al. 1993; Willich et al. 1993; Albert et al. 2000]. Epidemiologic studies among fire fighters have shown that fire suppression, training, alarm response, or strenuous physical activity on the job, in the preceding 12 hours, increases the risk for a sudden cardiac event [Kales et al. 2003; Hales et al. 2007; Kales et al. 2007]. The FADO had performed a PRA less than an hour before he began SCBA maze training in full PPE. It is likely that the physical exertion required to perform the PRA and/or SCBA maze test probably triggered his sudden cardiac death.

\section{Occupational Medical Standards for Structural Fire Fighters}

To reduce the risk of sudden cardiac arrest or other incapacitating medical conditions among fire fighters, the National Fire Protection Association (NFPA) developed NFPA 1582, Standard on Comprehensive Occupational Medical Program for Fire Departments [NFPA 2013]. This voluntary industry standard provides (1) the components of a preplacement and annual medical evaluation and (2) medical fitness for duty criteria. The FADO had a medical evaluation consistent with NFPA 1582 several months before his death. As part of his medical evaluation the FADO had an exercise stress test performed as is recommended for individuals over 45 years of age with two or more cardiovascular disease risk factors. The test was a symptom-limited test to maximum, apparently using a modified Bruce Protocol with shortened exercise stages, and the FADO achieved a heart rate of $107 \%$ of agepredicted maximum heart rate. An exercise stress test is a diagnostic test that monitors electrocardiographic responses to exercise. Like all diagnostic testing, misclassification of patients occurs some times. Test sensitivity refers to the percentage of times a test correctly identifies 


\section{Fire Apparatus Driver Operator Suffers Fatal Cardiac Event During Fire Department Training - Maryland}

individuals with CHD. Research indicates that exercise stress tests accurately detects CHD approximately $70 \%$ of the time [Gianrossi et al. 1989]. A false-negative response, as occurred in this case, is when the test results are normal in a person with CHD.

\section{Recommendations}

Recommendation \#1: Ensure that all fire fighters receive an annual medical evaluation consistent with NFPA 1582, Standard on Comprehensive Occupational Medical Program for Fire Departments.

Discussion: Guidance regarding the content and frequency of these medical evaluations can be found in NFPA 1582 and in the International Association of Fire Fighters (IAFF)/International Association of Fire Chiefs (IAFC) Fire Service Joint Labor Management Wellness/Fitness Initiative [NFPA 2013; IAFF, IAFC 2008]. These evaluations are performed to determine fire fighters' medical ability to perform duties without presenting a significant risk to the safety and health of themselves or others. The FADO had received a complete FD medical evaluation, including an exercise stress test, just 7 months before his death. Although the medical evaluation did not prevent this fatality, medical evaluations remain the best way to screen for incapacitating cardiovascular events.

\section{Recommendation \#2: Ensure fire fighters are cleared for duty by a physician knowledgeable about} the physical demands of firefighting, the personal protective equipment used by fire fighters, and the various components of NFPA 1582.

Discussion: According to NFPA 1582 and the IAFF/IAFC Fire Service Joint Labor Management Wellness/Fitness Initiative, the FD should have an officially designated physician who is responsible for guiding, directing, and advising the members with regard to their health, fitness, and suitability for duty [NFPA 2013; IAFF/IAFC 2008]. The physician should review job descriptions and essential job tasks required for all FD positions to understand the physiological and psychological demands of firefighting and the environmental conditions under which fire fighters perform, as well as the personal protective equipment they must wear during various types of emergency operations. In addition, this physician should oversee all fitness for duty recommendations provided by PCPs and have the final authority for all medical fitness for duty decisions. The FD where the FADO was working at the time of his death requires firefighters to provide their PCP with a list of firefighting tasks and then to provide a signed medical clearance. In this case, the FADO was also a volunteer firefighter with a FD that required a 1582 compliant medical evaluation in an occupation medicine clinic.

\section{Recommendation \#3: Phase in a mandatory comprehensive wellness and fitness program to reduce} risk factors for cardiovascular disease and improve cardiovascular capacity.

Discussion: Guidance for fire department wellness/fitness programs to reduce risk factors for cardiovascular disease and improve cardiovascular capacity is found in NFPA 1583, Standard on Health-Related Fitness Programs for Fire Fighters, the IAFF/IAFC Fire Service Joint Labor Management Wellness/Fitness Initiative, the National Volunteer Fire Council Health and Wellness Guide, and in Firefighter Fitness: A Health and Wellness Guide [USFA 2004; IAFF, IAFC 2008; 


\section{Fire Apparatus Driver Operator Suffers Fatal Cardiac Event During Fire Department Training - Maryland}

NFPA 2008; Schneider 2010]. Worksite health promotion programs have been shown to be cost effective by increasing productivity, reducing absenteeism, and reducing the number of work-related injuries and lost work days [Stein et al. 2000; Aldana 2001]. Fire service health promotion programs have been shown to reduce CHD risk factors and improve fitness levels, with mandatory programs showing the most benefit [Dempsey et al. 2002; Womack et al. 2005; Blevins et al. 2006]. A study conducted by the Oregon Health and Science University reported a savings of more than \$1 million for each of four large fire departments implementing the IAFF/IAFC wellness/fitness program compared to four large fire departments not implementing a program. These savings were primarily due to a reduction of occupational injury/illness claims with additional savings expected from reduced future nonoccupational healthcare costs [Kuehl et al. 2013]. The FD has a standard operating procedure designed to assist members achieve and maintain optimal health and that stipulates that every member should attempt a physical fitness assessment every year. The FD also has peer fitness trainers available to assist members with a training program. The department should embrace a mandatory fitness program that provides for protected time for members to work out on duty.

The following recommendation would not have prevented the FADO's death, but NIOSH investigators include it to address general safety and health issues.

\section{Recommendation \#4: Consider providing on-scene emergency medical services with advanced life support and transport capability during the PRA as is recommended during live fire training.}

Discussion: NFPA 1403 requires emergency medical services be on scene during all live fire exercises including exterior props. Emergency medical services are defined as "the provision of treatment, such as first aid, CPR, basic life support, advanced life support, and other pre-hospital procedures including ambulance transportation, to patients.” [NFPA 2007]. These EMS personnel must remain on scene until all exercises are concluded, equipment is restored to an in-service condition, and students are released. Because of the physical demands of performing physical ability testing in full personal protective equipment, the FD should consider having EMS support available during the PRA. In this case, EMS personnel were on-scene and it did not change the outcome of the case. However, it may be beneficial to ensure that EMS is on-scene as a matter of policy.

\section{Recommendation \#5: Adopt procedures to make sure that firefighters are properly supervised while they are doing training.}

Discussion: The FADO was accompanied inside the Maze by a fellow crew member who was able to summon help quickly when the FADO collapsed. Although there were no delays in providing care in this case, NIOSH recommends that the FD review policies to ensure that all firefighters are supervised by a qualified instructor during training as required by NFPA 1500 Standard on Fire Department Occupational Safety and Health Program [NFPA 2013]. Additionally, the FD should consider issuing radios to participants inside the Maze so that help can be summoned quickly if necessary. 


\section{Fire Apparatus Driver Operator Suffers Fatal Cardiac Event During Fire Department Training - Maryland}

\section{References}

AHA [2012]. Understand your risk of heart attack. American Heart Association. [http://www.heart.org/HEARTORG/Conditions/HeartAttack/UnderstandYourRiskofHeartAttack/Unde rstand-Your-Risk-of-Heart-Attack_UCM_002040_Article.jsp]. Date accessed: November 2014.

Albert CM, Mittleman MA, Chae CU, Lee IM, Hennekens CH, Manson JE [2000]. Triggering of sudden death from cardiac causes by vigorous exertion. N Engl J Med 343(19):1355-1361.

Aldana SG [2001]. Financial impact of health promotion programs: a comprehensive review of the literature. Am J Health Promot 15:296-320.

Barnard RJ, Duncan HW [1975]. Heart rate and ECG responses of firefighters. J Occup Med 17(4): 247-250.

Blevins JS, Bounds R, Armstrong E, Coast JR [2006]. Health and fitness programming for fire fighters: does it produce results? Med Sci Sports Exerc 38(5):S454.

CDC [2014]. Assessing your weight. Centers for Disease Control and Prevention.

[http://www.cdc.gov/healthyweight/assessing/index.html]. Date accessed: November 2014.

Davies MJ [1992]. Anatomic features in victims of sudden coronary death. Coronary artery pathology. Circulation 85[Suppl I]:I-19-24.

Dempsey WL, Stevens SR, Snell CR [2002]. Changes in physical performance and medical measures following a mandatory firefighter wellness program. Med Sci Sports Exerc 34(5):S258.

Farb A, Tang AL, Burke AP, Sessums L, Liang Y, Virmani R [1995]. Sudden coronary death: frequency of active lesions, inactive coronary lesions, and myocardial infarction. Circulation 92(7):1701-1709.

Gianrossi R, Detrano R, Mulvihill D, et al. [1989]. Exercise-induced ST depression in the diagnosis of coronary artery disease: a meta-analysis. Circulation 80:87-98.

Hales T, Jackson S, Baldwin T [2007]. NIOSH Alert: Preventing Fire Fighter Fatalities Due to Heart Attacks and Other Sudden Cardiovascular Events. Department of Health and Human Services, Public Health Service, Centers for Disease Control and Prevention, National Institute for Occupational Safety and Health Publication No. 2007-133. [http://www.cdc.gov/niosh/docs/2007-133/]. Date Accessed: November 2014.

IAFF, IAFC [2008]. The fire service joint labor management wellness/fitness initiative. 3rd ed. Washington, DC: International Association of Fire Fighters, International Association of Fire Chiefs. 


\section{Fire Apparatus Driver Operator Suffers Fatal Cardiac Event During Fire Department Training - Maryland}

Kales SN, Soteriades ES, Christoudias SG, Christiani DC [2003]. Fire fighters and on-duty deaths from coronary heart disease: a case control study. Environ Health 2(1):14.

Kales SN, Soteriades ES, Christophi CA, Chirstiani DC [2007]. Emergency duties and deaths from heart disease among fire fighters in the United States. New Engl J Med 356(12):1207-1215.

Kuehl KS, Elliot DL, Goldberg L, Moe EL, Perrier E, Smith J [2013]. Economic benefit of the PHLAME wellness programme on firefighter injury. Occup Med 63(3):203-209.

Lemon PWR, Hermiston RT [1977]. The human energy cost of fire fighting. J Occup Med 19(8):558565

Levy D, Garrison RJ, Savage DD, Kannel WB, Castelli WP [1990]. Prognostic implications of echocardiographically determined left ventricular mass in the Framingham Heart Study. N Engl J Med 323(24):1706-1707.

Libby P [2008]. The pathogenesis, prevention, and treatment of atherosclerosis. In: Fauci AS, Braunwald E, Kasper DL, Hauser SL, Longo DL, Jameson JL, Loscalzo J, eds. Harrison’s principles of internal medicine. 17th ed. New York: McGraw-Hill, pp. 1501-1509.

Manning JE, Griggs TR [1983]. Heart rates in fire fighters using light and heavy breathing equipment: Similar near-maximal exertion in response to multiple work load conditions. J Occup Med. 25(3): 215218.

Mittleman MA, Maclure M, Tofler GH, Sherwood JB, Goldberg RJ, Muller JE [1993]. Triggering of acute myocardial infarction by heavy physical exertion. N Engl J Med 329(23):1677-1683.

NFPA [2008]. Standard on health-related fitness programs for fire fighters. Quincy, MA: National Fire Protection Association. NFPA 1583.

NFPA [2013]. Standard on comprehensive occupational medical program for fire departments. Quincy, MA: National Fire Protection Association. NFPA 1582.

NFPA [2013]. Standard on Fire Department occupational safety and health program. Quincy, MA: National Fire Protection Association. NFPA 1500.

National Cholesterol Education Program [2002]. Third Report of the National Cholesterol education Program (NCEP) Expert Panel on Detection, Evaluation, and Treatment of High Blood Cholesterol in Adults (Adult treatment Panel III). NIH Publication No. 02-5215. National Institutes of Health, National Heart, Lung, and Blood Institute. Washington: Government Printing Office.

Schneider EL [2010]. Firefighter fitness: a health and wellness guide. New York: Nova Science Publishers. 


\section{Fire Apparatus Driver Operator Suffers Fatal Cardiac Event During Fire Department Training - Maryland}

Shah PK [1997]. Plaque disruption and coronary thrombosis: new insight into pathogenesis and prevention. Clin Cardiol 20(11 Suppl2):II-38-44.

Siegel RJ [1997]. Myocardial hypertrophy. In: Bloom S, ed. Diagnostic criteria for cardiovascular pathology acquired diseases. Philadelphia, PA: Lippencott-Raven, pp. 55-57.

Smith DL, Manning TS, Petruzzello SJ [2001]. Effect of strenuous live-drills on cardiovascular and psychological responses of recruit fire fighters. Ergonomics 44(3): 244-254

Smith DL, Petruzzello SJ, Kramer JM, Warner SE, Bone BG, Misner JE [1995]. Selected physiological and psychobiological responses of physical activity in different configurations of firefighting gear. Ergonomics 38(10): 2065-2077.

Stein AD, Shakour SK, Zuidema RA [2000]. Financial incentives, participation in employer sponsored health promotion, and changes in employee health and productivity: HealthPlus health quotient program. J Occup Environ Med 42(12):1148-1155.

Tofler GH, Muller JE, Stone PH, Forman S, Solomon RE, Knatterud GL, Braunwald E [1992]. Modifiers of timing and possible triggers of acute myocardial infarction in the Thrombolysis in Myocardial Infarction Phase II (TIMI II) Study Group. J Am Coll Cardiol 20(5):1049-1055.

USFA [2004]. Health and wellness guide. Emmitsburg, MD: Federal Emergency Management Agency; United States Fire Administration. Publication No. FA-267.

Willich SN, Lewis M, Lowel H, Arntz HR, Schubert F, Schroder R [1993]. Physical exertion as a trigger of acute myocardial infarction. N Engl J Med 329(23):1684-1690.

Womack JW, Humbarger CD, Green JS, Crouse SF [2005]. Coronary artery disease risk factors in firefighters: effectiveness of a one-year voluntary health and wellness program. Med Sci Sports Exerc 37(5):S385

\section{Investigator Information}

This incident was investigated by the NIOSH Fire Fighter Fatality Investigation and Prevention Program, Cardiovascular Disease Component located in Cincinnati, Ohio. Denise L. Smith, Ph.D, led the investigation and coauthored the report. Dr. Smith is professor of Health and Exercise Sciences, and Director of the First Responder Health and Safety Laboratory at Skidmore College. She is a 


\section{Fire Apparatus Driver Operator Suffers Fatal Cardiac Event During Fire Department Training - Maryland}

member of the NFPA Technical Committee on Occupational Safety and Health. Dr. Smith was working as a contractor with the NIOSH Fire Fighter Fatality Investigation and Prevention Program, Cardiovascular Disease Component during this investigation. Thomas Hales, MD, MPH, provided medical consultation and coauthored the report. Dr. Hales is a member of the NFPA Technical Committee on Occupational Safety and Health, and Vice Chair of the Public Safety Medicine Section of the American College of Occupational and Environmental Medicine (ACOEM).

\section{Disclaimer}

Mention of any company or product does not constitute endorsement by the National Institute for Occupational Safety and Health (NIOSH). In addition, citations to Web sites external to NIOSH do not constitute NIOSH endorsement of the sponsoring organizations or their programs or products. Furthermore, NIOSH is not responsible for the content of these Web sites. 


\section{Fire Apparatus Driver Operator Suffers Fatal Cardiac Event During Fire Department Training - Maryland}

\section{Appendix One Autopsy Findings}

- Heart size and structure

o Heart weight $=600$ grams (expected weight 401 grams; lower $95 \%$ confidence limit 302 grams and upper 95\% confidence limit 531 grams for a male weighing 229-234 pounds) [Silver and Silver 2001]

o Left ventricular hypertrophy $(1.3 \mathrm{~cm})$. Normal at autopsy is $0.76-0.88 \mathrm{~cm}$ [Colucci and Braunwald 1997]

o Heart valves are within normal limits

- Coronary arteries

o Moderate to severe atherosclerotic stenosis

- $90 \%$ stenosis of the first diagonal branch of the left anterior descending artery

o $75 \%$ stenosis of the left anterior descending artery

o No coronary thrombosis

- No evidence for a pulmonary embolus

- Negative drug screen

\section{References}

Colucci WS, Braunwald E [1997]. Pathophysiology of heart failure. In: Braunwald, ed. Heart disease. 5th ed. Philadelphia, PA: W.B. Saunders Company, p. 401.

Silver MM, Silver MD [2001]. Examination of the heart and of cardiovascular specimens in surgical pathology. In: Silver MD, Gotlieb AI, Schoen FJ, eds. Cardiovascular pathology. 3rd ed. Philadelphia, PA: Churchill Livingstone, pp. 8-9. 